\title{
Uma Análise Curricular das Disciplinas de Algoritmos e Lógica Computacional em Cursos de Licenciatura em Informática e Computação
}

\author{
Jeanne da Silva B. Bulão ${ }^{1}$, Edmilson B. C. Neto ${ }^{1}$, Keila Cruz Moreira ${ }^{1}$ \\ ${ }^{1}$ Instituto Federal de Educação, Ciência e Tecnologia do Rio Grande do Norte - \\ Licenciatura em Informática - Natal - RN - Brasil \\ jeannes.barbosas@gmail.com, \{edmilson.campos, keila.cruz\}@ifrn.edu.br
}

\begin{abstract}
This paper describes an analysis of the structure of the curricula of computational logic and algorithms in a degree in Computer Science compared to a national panorama of these components. The evaluated aspects such as time, supply period and contents were analyzed by students and teachers of the course and compared with a mapping of 34 documents from other courses of the same nature. The results of this work are important because they indicate dimensions and perspectives of the components, and can be used in revisions of courses and debates in the Central Structural Core.
\end{abstract}

Resumo. Este artigo descreve uma análise da estrutura dos planos curriculares de lógica computacional e algoritmos em um curso de Licenciatura em Informática em comparação com um panorama nacional desses componentes. Os aspectos avaliados como carga horária, período de oferta e conteúdos foram analisados por discentes e docentes do curso e comparados com um mapeamento realizado em 34 documentos de outros cursos de mesma natureza. Os resultados deste trabalho são importantes porque indicam dimensões e perspectivas dos componentes, e podem ser utilizados em revisões de cursos e debates nos Núcleos Centrais Estruturantes.

\section{Introdução}

O termo currículo, de forma geral, constitui-se em um conceito complexo e plural que orienta a prática docente. Para Grundy apud (1987, SACRISTÁN, 2008) o currículo não é apenas um conceito, mas uma construção cultural; um modo de organizar uma série de práticas educativas. O currículo é visto por Sacristán (2008) como a condensação ou expressão da função social e cultural da instituição escolar. Moreira e Candau (2007) corroboram com o tema quando afirmam que o currículo pode ser associado a diversas concepções e compreensões. As compreensões assumem representações tais como: (a) os conteúdos a serem ensinados e aprendidos; (b) as experiências de aprendizagem escolares a serem vividas pelos alunos; (c) os programas pedagógicos elaborados por professores, escolas e sistemas educacionais; (d) os objetivos a serem alcançados por meio do processo de ensino; (e) os processos de avaliação que terminam por influir nos conteúdos e nos procedimentos selecionados nos diferentes graus da escolarização. Quanto às concepções de currículo, os autores afirmam que derivam dos diversos modos de como a educação é idealizada historicamente e das influências teóricas que a afetam e se fazem hegemônicas em determinado momento da história.

Nesse contexto, valendo-nos novamente de Moreira e Candau (2007) sobre as diversas manifestações e compreensões sobre o termo currículo, apontamos que para 
VII Congresso Brasileiro de Informática na Educação (CBIE 2018)

Anais do XXIV Workshop de Informática na Escola (WIE 2018)

este trabalho, o termo está relacionado aos planos de disciplinas de algoritmos e de lógica computacional dos cursos de Licenciatura em Informática e/ou Computação, e por consequência, a seus conteúdos, carga horária, período de oferta. Estes elementos mostram-se importantes porque condicionam a prática educativa conforme aponta Freire (2008). Para este autor, a prática educativa ocorre na presença de sujeitos do ensino e da aprendizagem, de um espaço-tempo pedagógico, de experiência gnosiológicas, de política, valores, sonhos, projetos e utopias que são utilizados pelos professores das disciplinas para elaborar suas estratégias e metodologias de ensino.

Não obstante a natureza das concepções, a temática currículo é relevante por aprofundar discussões que estão presentes na realidade escolar. Nos cursos de Licenciatura em Computação e/ou Informática, embora seja importante o estudo da temática, no âmbito desses cursos, os estudos ainda são incipientes. De modo que, trabalhos como o de Jonathan (2016) mostra-se relevante por suscitar discussões sobre o currículo em Computação e apontar o porquê de não sofrerem alterações.

Ainda que trabalhos no campo de currículo sejam escassos na área de Computação, pesquisas sobre alguns componentes curriculares dos cursos de Bacharelado e de Licenciatura em Informática e/ou Computação são comuns. Em quantidade significativa estudos buscam investigar problemas no processo de ensino e aprendizagem de componentes curriculares de programação e de algoritmos. Trabalhos como de Gomes e Mendes (2007), assim como os de Giraffa et al. (2012) apresentam causas para as dificuldades dos alunos nesses componentes e os aspectos relativos às causas das evasões nos cursos de Computação. Nessas pesquisas, os autores afirmam que esses problemas estão associados a dificuldades na formação básica em matemática e a estratégias pedagógicas tradicionais. Outras pesquisas descrevem estudos sobre soluções possíveis de serem aplicadas para melhorar o processo de ensino-aprendizagem nessas disciplinas. Pimentel et al. (2003), a exemplo, apontam a utilização de sistemas inteligentes ou ambientes auxiliados por computador para melhorar as atividades práticas da disciplina, facilitando o aprendizado do aluno. Borges (2000) e Rodrigues (2004), por outro lado, preocupam-se com a questão da metodologia empregada pelos professores. Para estes autores o desenvolvimento de um plano de ensino baseado em exemplos que possuam relação com o mundo real aproximam os alunos das soluções, e consequentemente, favorece a internalização dos conteúdos das aulas.

Em relação a temática do currículo em Computação, estudos sobre a estrutura curricular de planos e Projetos Pedagógicos de Cursos de Licenciatura em Informática e/ou Computação têm surgido, e alguns trabalhos acadêmicos apontam a importância do tema. Dentre esses relatados, destacamos o trabalho de Prietch e Pazeto (2009) que analisaram o currículo do curso de Licenciatura Plena em Informática da Universidade Federal de Mato Grosso (UFMT); e o mapeamento nos cursos de Licenciatura em Computação realizado por Prietch e Pazeto (2010), que apresentam uma proposta de matriz curricular baseada em documentos publicados em nível nacional. De forma semelhante, Bezerra e Silveira (2011) discutem um panorama do curso de Licenciatura em Computação considerando o cenário nacional e um estudo de caso em um curso no estado de São Paulo a fim de criar um perfil desses cursos. Contudo, esses trabalhos não analisaram em profundidade aspectos estruturais que compõe os planos de algoritmos e lógica computacional e que influenciam o planejamento da prática educativa, como os já mencionados: conteúdos, carga horária e período de oferta, entre outros. 
Em relação aos resultados, o trabalho demostra que os docentes da Licenciatura em Informática do IFRN, campus Natal Zona Norte, avaliam a carga horária atual de 60h da disciplina de algoritmos como adequada ao ensino do componente - carga horária igualmente adotada na maioria dos cursos da área no Brasil —, de forma contrária, os discentes do curso defendem uma carga horária superior para prática. Além disso, ambos os públicos-alvo apontam como necessário a exclusão de conteúdos como ponteiros e funções recursivas, bem como defendem uma revisão no plano de lógica computacional para melhor contextualizá-la com o ensino de algoritmos.

A partir dos resultados da pesquisa novas discussões poderão surgir e contribuir no processo de revisão periódica dos Projetos Pedagógicos de Cursos, assim como colaborar nos debates dos Núcleos Centrais Estruturantes (NCE) e Núcleos Docentes Estruturantes (NDE) dos cursos de mesma natureza. Os NCE e NDE são importantes porque debatem e propõe melhorias para os cursos, colaborando assim para que os cursos acompanhem os avanços na qualidade do ensino superior.

Os Núcleos Centrais Estruturantes (NCE) têm, de forma geral, o objetivo de garantir a unidade da ação pedagógica e do desenvolvimento do currículo nas IES, com vistas a manter a de qualidade do ensino, de acordo com o Projeto Político-Pedagógico da instituição e com o Projeto Pedagógico dos cursos ofertados. De forma semelhante, os Núcleos Docentes Estruturantes (NDE) são grupos formados por docentes e possuem caráter consultivo de acompanhamento dos cursos de graduação, que atua no processo de concepção, consolidação e contínua atualização do projeto pedagógico do curso (PPC), buscando a continua qualidade dos cursos.

No que refere aos cursos de Licenciatura em Informática e/ou Computação, por exemplo, há a Resolução CNE/CES no 5, de 16 de novembro de 2016, trata das características dos egressos e de sua formação, discutindo inclusive as habilidades e as competências que devem ter os habilitados nesses cursos.

Nesse contexto, trabalhos como este incentivam discussões sobre os planos de cursos dos componentes e apresentam perspectivas diferentes daquelas que estão presentes há certo tempo, e que colaboram para que componentes curriculares de programação e algoritmo não sejam associados a evasões e desestímulos nos cursos de Computação.

\section{Procedimento metodológico}

Esta seção descreve os procedimentos metodológicos adotados neste estudo para investigar a opinião de discentes e docentes do curso de Licenciatura em Informática da Instituição de Ensino Superior (IES) analisada.

\subsection{Objetivo de pesquisa}

Em particular, o estudo visava investigar os seguintes aspectos estruturantes dos planos de algoritmos e lógica computacional da Licenciatura em Informática do IFRN, campus Natal Zona Norte, e correlacioná-los com panorama nacional: (i) nomenclatura que melhor define as disciplinas; (ii) período e pré-requisitos ideais para oferta dessas disciplinas no curso; (iii) carga horária prática/teórica mais recomendada; (iv) os conteúdos imprescindíveis ou que devem ser suprimidos dos planos.

\subsection{Seleção dos públicos-alvo}


Esses aspectos foram avaliados a partir da ótica de: (i) discentes e (ii) docentes do curso e confrontado os resultados dessa avaliação isolada com o (iii) panorama nacional de outros 34 cursos de Licenciatura em Informática e Computação em Instituições de Ensino Superior (IES) públicas do Brasil, mapeados anteriormente em Bulcão et al. (2017). Na pesquisa atual, para seleção dos públicos-alvo (i) e (ii), foram consideramos habilitados os professores da área de sistemas de informação aptos a lecionar os componentes investigados; e discentes cursando a partir do $2^{\circ}$ período do curso, que são aqueles que já haviam cursado a disciplina de lógica computacional e que estavam estudando a disciplina de algoritmos.

\subsection{Extração de dados}

A extração de dados para os dois públicos-alvo ocorreu entre os meses de março e maio de 2017, por meio da aplicação de formulário eletrônico, apoiado na perspectiva de Marconi e Lakatos (2003). Ao todo 09 docentes e 39 discentes responderam ao formulário. Os dados dos outros 34 cursos de Licenciatura em Informática e Computação de IES públicas do Brasil foram extraídos e mapeados em Bulcão et al. (2017) e são apenas referenciados nesse estudo.

\subsection{Análise dos dados}

A avaliação dos dados coletados ocorreu por meio de uma análise comparativa dos resultados da análise dos planos com os dados coletados e já analisados do mapeamento nacional, utilizando os métodos comparativo e dedutivo na perspectiva de Gil (2008).

\section{Resultados}

Os resultados obtidos por meio dos procedimentos metodológicos utilizados na pesquisa foram sistematizados nesta seção a partir da análise do plano de algoritmos e lógica computacional inicialmente na perspectiva discente (3.1) e seguida pela visão docente (3.2). Após, finalizamos os resultados com duas tabelas comparativas das avaliações dos discentes e docentes com o cenário nacional encontrado (3.3).

Particularmente, descrevemos os resultados considerando não apenas o valor percentual que se destaca como representação da maioria. $\mathrm{Na}$ análise há uma tentativa de ir além do factual, perpassa pelas perspectivas quantitativa e qualitativa, considerando os percentuais que se destacam, sem desprezar as tendências resultantes do somatório dos outros percentuais que podem representar uma nova dimensão/visão do currículo tomado para análise (planos de cursos).

\subsection{Avaliação dos planos de disciplinas na perspectiva discente}

\subsubsection{Nome que melhor define a disciplina de algoritmos}

Para os discentes do curso de Licenciatura em Informática do IFRN, o nome que melhor define a disciplina de ensino de algoritmos é introdução à lógica de programação. Para $41 \%$ dos 39 discentes que responderam o formulário online, essa disciplina deveria se chamar introdução à programação. Todavia, se somados todos os demais percentuais, percebe-se que entre os discentes não há clareza quanto ao melhor nome para se referir ao componente analisado.

\subsubsection{Periodo/semestre letivo ideal de oferta}


VII Congresso Brasileiro de Informática na Educação (CBIE 2018)

Anais do XXIV Workshop de Informática na Escola (WIE 2018)

Aproximadamente $72 \%$ dos discentes acreditam que o ensino de lógica computacional e algoritmos não podem ocorrer concomitantemente. Apenas $28 \%$ considera essa possibilidade. Alguns discentes acreditam que a disciplina de algoritmos precisa de um conhecimento prévio, outros compreendem que em períodos diferentes as duas disciplinas funcionam melhor, todavia nenhum discente considerou a possibilidade de do componente de lógica computacional não ser ofertado, mesmo existindo a opção no formulário. Embora os discentes afirmem que estas disciplinas se complementam, para eles o ensino de lógica computacional deve ser inserido no $1^{\circ}$ período do curso, enquanto o componente de algoritmos deve ser aprendido apenas no $2^{\circ}$.

\subsubsection{Distribuição de Carga horária}

Em relação à carga horária, embora aproximadamente $26 \%$ dos discentes acreditem que 80 h é o tempo ideal para o ensino de algoritmos, falar em consenso não é possível, pois há um volume significativo de outras proposições que foram bem pontuadas. Nesse sentido, o que se pode dizer é que apenas $23 \%$ concordam com a carga horária de $60 \mathrm{~h}$ da atual ementa do curso, enquanto $77 \%$ consideram que a carga horária deve ser superior a esta.

\subsubsection{Distribuição de Conteúdos}

Em relação aos conteúdos, os entrevistados rejeitaram conteúdos mais específicos e menos relevantes do componente de algoritmos, tais como: biblioteca de funções, ponteiros, operadores de endereço, alocação dinâmica e listas. Observamos ainda que há um grande volume de respostas positivas em relação aos conteúdos de algoritmos e lógica computacional que buscam o desenvolvimento do raciocínio computacional do discente.

\subsection{Avaliação dos planos de disciplinas na perspectiva docente}

\subsubsection{Nome que melhor define a disciplina de algoritmos}

Para $50 \%$ dos docentes que responderam à pesquisa o nome de componente curricular que melhor define o ensino de algoritmos é algoritmos e técnicas de programação, nome atual do componente. Os demais pesquisados optam por algoritmos $(25 \%)$ e fundamentos de lógica $(12 \%)$.

\subsubsection{Periodo/semestre letivo ideal de oferta}

Quanto ao período, $50 \%$ dos docentes acreditam que o componente relativo ao ensino de algoritmos deve ser cursado já nos períodos iniciais do curso, no entanto, há um empate entre o $1^{\circ}$ e o $2^{\circ}$ periodo.

De acordo com $87,5 \%$ dos pesquisados os componentes de lógica e algoritmos não devem ser ofertados concomitantemente. Pois segundo esses docentes, o componente de lógica contribui no desenvolvimento do raciocínio lógico e prepara os discentes para posteriormente internalizar os conteúdos e práticas para $\mathrm{o}$ desenvolvimento de algoritmos.

$\mathrm{Na}$ pesquisa, alguns docentes sugerem que o ensino dos conteúdos relativos à lógica computacional poderia ser inserido no componente de algoritmos sem prejuízo para o bom desenvolvido do discente posteriormente no curso. Na experiência de outros professores essa realidade favorece o ensino do conteúdo de algoritmos, pois o discente 
VII Congresso Brasileiro de Informática na Educação (CBIE 2018)

Anais do XXIV Workshop de Informática na Escola (WIE 2018)

não irá ver os conteúdos e as técnicas de programação em outro período, mas no mesmo, o que facilita a retomada dos conceitos.

Para o ensino do componente de lógica computacional, $75 \%$ dos pesquisados afirmam que o ensino de lógica deve ocorrer no $1^{\circ}$ período, isto porque consideram essa disciplina importante para à aprendizagem dos conteúdos do componente de algoritmos. Segundo os docentes, o ensino de lógica antes do ensino de conteúdos de algoritmos materializa e condiciona uma estrutura conceitual de mediação para os novos saberes que serão mediados no componente seguinte. Por outro lado, $12,5 \%$ dos docentes acreditam que a disciplina de lógica computacional deve ser vista no $2^{\circ}$ período, enquanto o mesmo número acredita que deve ser cursada sempre antes do componente de ensino de algoritmos.

Em face das discussões sobre o período de oferta dos componentes investigados chama atenção o fato do plano do componente de lógica computacional possuir indicação de que essa disciplina é importante, não especificamente para algoritmo, mas para a disciplina de eletrônica digital. Isto ocorre em razão dos conteúdos da base científica indicar conceitos que são utilizados posteriormente no estudo de circuitos digitais, tais como tabela verdade e conectivos. Essa mesma realidade também foi encontrada em outros documentos de cursos.

\subsubsection{Distribuição de Carga horária}

No que se refere à carga horária do componente de algoritmos, embora $75 \%$ dos docentes afirmem que a carga horária atual de 60horas do componente - mesma carga horária encontrada no cenário nacional - é suficiente para o ensino dos conteúdos e para bom sucesso da disciplina. Para $62 \%$ dos entrevistados a carga horária deveria ser superior a 75 horas.

\subsubsection{Distribuição de Conteúdos}

De acordo com pesquisados, o conteúdo relativo ao ensino de algoritmos deve abarcar temas básicos de ensino de programação. Novamente, assim como nos discentes, ocorre um distanciamento quanto ao ensino de ponteiros, alocação dinâmica e listas. Para os docentes, os discentes devem cursar conteúdos que os permitam criar laços de repetição e tratar dados, inserir e ler dados, assim como utilizar comandos básicos de programação. Nos conteúdos relativos ao ensino de lógica computacional, os discentes consideram a lógica proposicional e de predicados como sendo necessárias para o bom desenvolvimento dos discentes. Entretanto, discordam do plano atual apenas em temas e conteúdos mais específicos tais como: axiomas e inferências, argumentos válidos, limitações da lógica de predicados etc..

\subsection{Comparação da análise dos discentes e docentes com o cenário nacional}

Em relação à lógica computacional, o cenário nacional encontrado sugere que os conteúdos dessa disciplina são ofertados maior profundidade no curso de Licenciatura em Informática do IFRN. Para os discentes e docentes os conteúdos de lógica computacional devem ser vistos em profundidade, contemplando recursão, tautologias e argumentos válidos.

Nesse sentido, o que podemos afirmar é que no curso investigado, assim como todos os outros analisados anteriormente, precisa rever esse componente, verificando entre outras coisas, sua relevância para o global do curso e a validade desses conteúdos 
VII Congresso Brasileiro de Informática na Educação (CBIE 2018)

Anais do XXIV Workshop de Informática na Escola (WIE 2018)

para o egresso. Pois conforme Gil (2015) os conteúdos estão associados diretamente ao quanto significativo e importante estes são para atender as demandas dos discentes em determinada época ou período.

Quanto ao período de oferta às três realidades sugerem que esse componente deve ser ofertado no $1^{\circ}$ período. Todavia, anteriormente, em outro trabalho nosso, essa realidade foi percebida no cenário nacional com algumas alterações. Foi visto a presença da oferta dessa disciplina em dois outros períodos, no $5^{\circ}$ e no $3^{\circ}$ período. Quando ofertada no $3^{\circ}$ período, a disciplina de lógica computacional foi vista, algumas vezes, depois do componente de algoritmos, embora esta realidade não tenha ocorrido com grande frequência, ainda assim nos faz pensar que talvez essas disciplinas não estejam, necessariamente, tão interligadas quanto está no imaginário de professores e alunos.

Em relação à carga horária de lógica computacional, optamos por não questionar aos discentes e docentes porque se observou raríssima alteração no tempo de curso dessa disciplina. A carga horária de lógica computacional, basicamente se manteve em 60horas, com rara variação de 30horas quando visto apenas conteúdos introdutórios como os de raciocínio lógico, tais como tabela verdade e lógica de proposicional.

No mapeamento nacional, a carga horária mais comum foi de 60horas, a mesma preferida por professores do curso analisado. Entretanto para os discentes esta deveria ser de 80horas.

Diante disto, considerando este semanário de divergência no quadro comparativo podemos indicar diante do foi pesquisado que o desejo dos discentes por mais tempo para disciplina está associado ao próprio perfil do aluno do curso. Grande parte dos discentes do curso analisado estuda e trabalha, para além costumam ter dificuldades com a tecnologia (linguagem adotada pelo professor) empregada no ensino do componente, pois precisam de tempo para estudar sua estrutura e após começar a utilizá-la em seus algoritmos.

Para contextualizar quadro exposto, apontamos que na análise qualitativa dos dados, observamos que no cenário nacional há uma tendência nos documentos dos cursos. Uma parcela significativa dos cursos opta por tempo pedagógico superior a 75horas para o componente de algoritmos. Assim, a avaliação dos discentes em comparação com o cenário nacional, do ponto de vista qualitativo da pesquisa, indica que o componente de ensino de algoritmos deve ser inserido nas matrizes de cursos com carga horária superior a 60horas.

No quadro comparativo é possível perceber que no cenário nacional os planos costumam privilegiar conteúdos mais elementares, aqueles em que se é possível aplicar mais de uma tecnologia. Outro dado importante é que conteúdos pouco explorados no contexto nacional ainda são vistos como relevantes para docentes e discentes do curso analisado. Conteúdos como estruturas de dados heterogêneos, modulação e funções não frequentes nas ementas da maioria dos cursos, são considerados relevantes na opinião de docentes e discentes do curso.

Os conteúdos são importantes e devem ser visto associados aos objetivos do componente. Diante disso, Gil (2015) afirma que a escolha desses conteúdos deve obedecer a critérios que garantam minimamente que os discentes possam continuar sua formação após sua passagem pela geografia do componente em estudo. Dentre os 
VII Congresso Brasileiro de Informática na Educação (CBIE 2018)

Anais do XXIV Workshop de Informática na Escola (WIE 2018)

critérios, Gil (2015) aponta que os conteúdos devem ser significativos, úteis, flexíveis e adequados a diversidade dos alunos. Embora esses critérios sejam parâmetros e não uma regra, considerar esses elementos de estudo de conteúdos mostra-se como uma alternativa positiva de discussão sobre a problemática pela qual passa os componentes de programação e algoritmos e assim garantir menos ruídos no processo de aprendizagem dessas disciplinas.

\section{Considerações Finais}

Ao responderem a pesquisa os discentes e docentes expressaram suas opiniões sobre a organização didático-pedagógica do currículo dos componentes investigados, apontando, por exemplo, suas experiências de aprendizagem e ensino de algoritmos e lógica computacional. Dentre os relatos destacamos, a experiência exitosa de um docente que afirma ter tido sua melhor experiência de ensino quando lecionou em uma disciplina do $1^{\circ}$ período com carga horária superior às $60 \mathrm{~h}$, de ensino de algoritmos e de lógica computacional.

Quanto aos discentes, alguns apontam que as disciplinas de algoritmos e lógica computacional deveriam ser ensinadas de maneira mais interdisciplinar. Para esses discentes, o componente de lógica computacional costuma ser ensinado sem conexão com o de algoritmos. Esse apontamento realizado pelos discentes é bastante singular, pois todos os docentes e mesmo os discentes afirmam que é necessário estudar lógica computacional primeiro para depois se aprender algoritmos, sendo então muito difícil não interpretar que conteúdos de lógica computacional são continuados em algoritmos. Porém se isso for verdade, seria impossível não haver uma relação, uma interligação entre os dois componentes. Se de fato ocorre um ensino isolado do componente de lógica computacional, o que isso talvez indique é que lógica computacional, não necessariamente, precisa ser ofertada, ou se ofertada, não precisa, necessariamente, o ser antes de algoritmos.

Em relação às demandas de ensino e aprendizagem de docentes e discentes respectivamente, destacamos que os planos atuais de algoritmos e técnicas de programação da IES estudada, bem como de lógica computacional em comparação com o cenário nacional podem não mais estar de acordo às necessidades de aprendizagem dos discentes. Isto porque os conteúdos que estão dispostos nos planos, devem ser cursados em uma carga horária que limita o ensino do professor e a aprendizagem dos alunos em 4 horários de aula semanais. Embora se saiba que o processo de aprendizagem desses componentes ocorra de forma contínua extraclasse, à carga horária atual parece não ser suficiente para um bom aproveitamento do curso, considerando que muitos dos discentes trabalham e utilizam o tempo na instituição para desenvolver suas atividades, estudar e pesquisar. No que se refere ao componente de lógica computacional, a pesquisa indica que é necessário rever o período de oferta para que ocorra maior interdisciplinaridade e integração com o componente de algoritmos e técnicas de programação.

\section{Referências}

Bezerra, L. N. M. \& Silveira, I. F. (2011) Licenciatura em Computação no Estado de São Paulo: Uma Análise Contextualizada e um Estudo de Caso. In: XIX Workshop sobre Educação em Computação, Natal-RN. 
VII Congresso Brasileiro de Informática na Educação (CBIE 2018)

Anais do XXIV Workshop de Informática na Escola (WIE 2018)

Borges, M. A. F. (2000) Avaliação de uma Metodologia Alternativa para a Aprendizagem de Programação. VIII WEI 2000. Curitiba, PR, Brasil.

Bulcão, J. S. B; Campos Neto, E. B \& Keila, C.M.. (2017). Mapeamento sobre o Ensino de Algoritmo e Lógica Computacional nos Cursos de Licenciatura em Informática e Computação em Instituições de Ensino Superior no Brasil. In: II Congresso sobre Tecnologias na Educação (Ctrl+E 2017), Mamanguape - Paraíba.

Freire, P. Coleção Dizer a Palavra Pedagogia do compromisso: América Latina e educação popular. Indaiatuba: Vilas das letras, 2008.

Gil, A. C. Métodos e técnicas de pesquisa social. São Paulo: Atlas, 2008.

Gil, A.C. Didática do ensino superior. São Paulo: Atlas, 2015.

Giraffa, L. M. M. \& Moraes, M. C. O desafio de ensinar a programar no primeiro nível em cursos de graduação: alternativas para conter a evasão. In: Segunda Conferencia Latino americana sobre el Abandono en la Educación Superior II CLABES, 2012, Porto Alegre. II CLABES. Madrid: CLABES, 2012. v. 1. p. 486-498.

Gomes, A. \& Mendes, A. J. (2007) Learning to Program - Difficulties Disponível em: $<$ http://icee2007.dei.uc.pt/proceedings/papers/411.pdf $>$. Acesso em: 05 mai. 2017. and Solutions. Proceedings do ICEE 2007, Coimbra, Portugal.

Jonathan, Miguel. Currículos de Computação: porque permanecem assim?. In: WEI24 ${ }^{\circ}$ Workshop sobre Educação em Computação-XXXVI Congresso da SociedadeBrasileira de Computação, http://ebooks. pucrs. br/edipucrs/anais/csbc/assets/2016/wei/06. pdf, Março. 2016.

Marconi, M. A. \& Lakatos, E. M.. Fundamentos de metodologia científica. 5. ed. - São Paulo: Atlas 2003.

Moreira, A. F. B. \& Candau, V. M.. Currículo, conhecimento e cultura: indagações sobre currículos. Brasília: Ministério da Educação/Secretaria de Educação Básica, 2007. Disponível em http://portal.mec.gov.br/seb/arquivos/pdf/Ensfund/indag3.pdf. Acesso: jun. 2017.

Pimentel, E. P., França, V. F. e Omar, N. A Caminho de um Ambiente de Avaliação e Acompanhamento Contínuo de Aprendizagem em Programação de Computadores. II Workshop de Educação em Computação e Informática do Estado de Minas Gerais (WEIMIG'2003). Poços de Caldas, MG, Brasil.

Prietch, S. S. \& Pazeto, T. A. (2010). Mapeamento de Cursos de Licenciatura em Computação seguido de Proposta de Padronização de Matriz Curricular. In: XVIII Workshop de Educação em Computação (WEI 2010), Anais do XXX Congresso da Sociedade Brasileira de Computação - CSBC 2010 páginas 921-930.

Prietch, S. S. \&Pazeto, T. A. (2009). Análise, Sugestões e Perspectivas de um Curso de Licenciatura em Informática. In: XVII Workshop sobre Educação em Computação. Anais do XXIX Congresso da Sociedade Brasileira de Computação. Bento Gonçalves: Editora da SBC, v. 1. p. 557-566.

Rodrigues, M. Experiências positivas para o ensino de algoritmos. IV Escola Regional de Computação Bahia-Sergipe. Feira de Santana, 2004. Homepage: http://www.uefs.br/erbase2004/documentos/weibase/Weibase2004Artigo001.pdf 
VII Congresso Brasileiro de Informática na Educação (CBIE 2018)

Anais do XXIV Workshop de Informática na Escola (WIE 2018)

Sacristán, J.G. O currículo: uma reflexão sobre a prática. Porto Alegre: Artmed, 2008. 